\section{A tribute to Eliot Slater}

M Roth and V Cowie, editors (pp 225; £10.) London, Gaskell Press, 1979.

This book is a Festschrift, written by his friends and colleagues to celebrate the 75th birthday of Dr Eliot Slater, one of the most productive and influential psychiatrists of his generation. Dr Slater will be known personally to many readers of the Journal, especially those who worked at the National Hospital or the Maudsley Hospital, and by repute to almost all other readers. The book is edited by two of his former co-authors: Sir Martin Roth, with whom (and the late Dr Mayer Gross) Dr Slater wrote the most important British textbook of psychiatry for many a decade, and Dr Valerie Cowie, with whom he wrote the well-known Textbook of Psychiatric Genetics. In this general literary field Dr Slater wrote, with Dr Sargant, the several editions of Physical Methods of Treatment in Psychiatry. He also, as Chief Editor, transformed the Journal of Mental Science into the British Journal of Psychiatry, encouraging research, scholarship and literacy as he did so. This was, perhaps, his greatest achievement.

The contributions to the Festschrift are intended, as the title suggests, to reflect Dr Slater's main interests:-the scientific aspects of clinical pyschiatry, the art of pathography and the science, to which he made so many contributions, of psychiatric genetics. Some of the essays are original and scientifically important. Others reassemble previous findings and present them anew in his honour. One, by Desmond Curran, is an unashamed chapter of reminiscence of the formative years in psychiatry of Dr Slater and his peers-or perhaps contemporaries is a better term. (It is worth getting hold of the book just to read that chapter.) There are also, as a bonus, two essays by Dr Slater himself, one on musicians, one on Hamlet.

The publication of this book is not an empty exercise, such as the publication of the proceedings of most international symposia. It is an act of homage to a great scientist and humanist and it should be read as such. It makes very agreeable reading.

JL GIBBONS
Functional Disorders of Memory Edited by JF Kihlstrom and FJ Evans (pp 395; illustrated; £15.25) Lawrence Erlbaum Assoc. New Jersey. 1979.

Memory has recently become of renewed interest to psychologists and clinicians. This book is directed mainly to the former but has some incidental interest to clinicians. It is concerned mainly with functional rather than organic disorders (though this division becomes difficult to sustain in considering the effect of ECT, anaesthesia and even old age) and perhaps as a result pays more attention than the usual psychological texts to human rather than animal models. It illustrates the recent tendency amongst psychologists to accept that a number of problems in the human situation will escape laboratory observation. Everyday phenomenology must also be discussed. While memory is the title of the book, amnesia inevitably intrudes and usefully and relevantly extends the field of study. This obverse of the coin introduces clinical material to psychologists and may also introduce clinicians to some of the problems posed by "normal" memory. Questions such as Freud's concept of childhood amnesia, which remains controversial both as to repression and its possible causes; memory and the ageing brain; postECT and anaesthetic memory defects; and post-hypnotic amnesia are considered in the light of recent views and findings in psychology. A chapter on remembering and forgetting in dream recall is also of interest and may later be correlated with the findings of EEG paradoxical sleep. A return to Bartlett's views on remembering, with their similarities to Head's perceptual "schemata", and the acceptance of Tulvig's separation of memory into episodic and somantic groups (itself a revival of past theories) will both be welcome to clinicians and allow a more useful dialogue between psychologists and neurologists. The book should have an interested though limited medical readership.

CWM WHITTY

Advances in Neurology Vol 25 Cerebrovascular Disorders and Stroke Edited by Goldstein, Murray, Bolis, Liana, Fieschi, Gorini, Sergio, Millikan (pp 350; \$38.35) Raven Press, New York.

From its position as one of the cinderellas of medical research cerebrovascular disease has emerged as one of the commonest topics of new monographs. In many ways this latest volume reads more like the proceedings of a symposium however, as there are 41 contributions of varying length and style.

In line with the current interest there are papers on barbituraie treatment of ischaemia, anti-platelet therapy and the extracranial-intracranial bypass operation; three potentially useful therapies in search of clear indications for the use. The coverage of new non-invasive investigative technology is disappointing dealing only with doppler sonography and radionucleide angiography. Oculoplethysmography and Doppler imaging techniques emerging as the front runners are not mentioned. Angiography only has three sides!

Amongst the papers on pathophysiology there are some excellent contributions by Hossman on the experimental basis for the treatment of cerebral ischaemia. Lassen on cerebral blood flow, and a review of drug effects on the cerebral circulation by Heiss. Among the authorities writing the clinical chapters are Marshall on the differential diagnosis of completed strokes, and Millikan on the transient ischaemic attack.

The highlight of this new volume are perhaps Fletcher McDowells balanced discussions on the indications for and results of medical and surgical treatment of T.I.A.'s. There are also five special contributions on the problem of stroke in children and young adults.

The strange balance and uneven quality detract from the overall value of this book but there are enough contributions of a high calibre to recommend those interested in the field to dip into it.

MJG HARRISON

Brain and Mind: Ciba Foundation Symposium 69 (new series) (pp 425; \$51.25). Amsterdam: Elsevier Excerpta Medica, 1979.

Much of this is heavy going but the 